\title{
Co-transplantation of mesenchymal stem cells maintains islet organisation and morphology in mice
}

\author{
C. L. Rackham • P. C. Chagastelles • N. B. Nardi • \\ A. C. Hauge-Evans $\cdot$ P. M. Jones • A. J. F. King
}

Received: 13 September 2010 / Accepted: 22 December 2010 /Published online: 26 January 2011

(C) Springer-Verlag 2011

\begin{abstract}
Aims/hypothesis Recent studies have shown that mesenchymal stem cells (MSCs) secrete several factors that improve survival and function of transplanted islets. Implantation of islets beneath the kidney capsule results in morphological changes, due to interactions of the graft with the host, thus impairing islet function. We co-transplanted MSCs with islets to determine their effects on the remodelling process and studied graft function in a mouse model of minimal islet mass.

Methods Islets were syngeneically transplanted, either alone or with kidney-derived MSCs, underneath the kidney capsule of streptozotocin-induced diabetic C57Bl/6 mice. Blood glucose levels were monitored and intraperitoneal glucose tolerance tests carried out. Hormone contents of grafts and pancreas were assessed by radioimmunoassay. Graft morphology and vascularisation were evaluated by immunohistochemistry.

Results MSCs improved the capacity of islet grafts to reverse hyperglycaemia, with $92 \%$ of mice co-transplanted with MSCs reverting to normoglycaemia, compared with $42 \%$ of those transplanted with islets alone. Average blood glucose concentrations were lower throughout the 1 month
\end{abstract}

C. L. Rackham and P. C. Chagastelles contributed equally to this study.

C. L. Rackham • A. C. Hauge-Evans · P. M. Jones •

A. J. F. King $(\bowtie)$

Diabetes Research Group, Division of Diabetes and Nutrition,

School of Medicine, King's College London,

London SE1 1UL, UK

e-mail: aileen.king@kcl.ac.uk

P. C. Chagastelles $\cdot$ N. B. Nardi

Laboratory of Immunogenetics, Department of Genetics,

Universida de Federal do Rio Grande do Sul,

Porto Alegre, RS, Brazil monitoring period in MSC co-transplanted mice. MSCs did not alter graft hormone content. Islets co-transplanted with MSCs maintained a morphology that more closely resembled that of islets in the endogenous pancreas, both in terms of size, and of endocrine and endothelial cell distribution. Vascular engraftment was superior in MSC co-transplanted mice, as shown by increased endothelial cell numbers within the endocrine tissue.

Conclusions/interpretation Co-transplantation of islets with MSCs had a profound impact on the remodelling process, maintaining islet organisation and improving islet revascularisation. MSCs also improved the capacity of islets to reverse hyperglycaemia.

Keywords Diabetes · Graft morphology · Islet architecture . Mesenchymal stem cells $\cdot$ Transplantation

\section{Abbreviations \\ IPGTT Intraperitoneal glucose tolerance test \\ MSCs Mesenchymal stem cells}

\section{Introduction}

The development of the Edmonton protocol led to marked improvements in the success rate of clinical islet transplantation [1]. Despite this, graft function progressively declines, with only $10 \%$ to $15 \%$ of patients remaining independent of insulin after 5 years [2-4]. One important confounding factor in islet transplantation is the loss of functional islets during the early post transplantation period [5-7], which has detrimental effects on the outcome of individual grafts, further exacerbating the scarcity of donor tissue. Important factors contributing to the loss of trans- 
planted islets include ischaemia due to inadequate vascularisation and deleterious responses of islet cells to an inflammatory, immunogenic environment [8]. Transplanted islets are avascular during the immediate post transplantation period [9] and must function in a hypoxic microenvironment [7], both of which contribute to ischaemic cell death and inflammatory events. An improved rate or extent of revascularisation of transplanted islets, or enhancement of islet survival should improve the outcome of islet transplantation.

Mesenchymal stem cells (MSCs) are adult progenitor cells, which can proliferate in vitro and give rise to differentiated mesenchymal cell types. MSCs have been isolated from many tissues and may be localised to a perivascular niche that is present in most, if not all, vascularised organs [10]. MSCs play a major role in tissue repair through localised immunosuppressive effects and through the release of soluble trophic factors to affect neighbouring cells [11]. These properties make MSCs excellent candidates for improving the survival of transplanted islets. Several recent studies in experimental animals have reported that co-transplantation of islets and MSCs produces superior outcomes to islet-alone grafts [1219]. To date, these beneficial effects have been largely attributed to direct or indirect actions of MSCs in promoting islet survival and function by enhancing graft revascularisation $[13,17,19]$ or by suppressing immune or inflammatory responses [12, 14-16, 18].

The kidney subcapsular site is most commonly used for islet transplantation in rodent studies [20], although this is known to result in remodelling of the islets within the graft tissue in terms of morphology and composition of endocrine cells [5, 21-23], which is associated with cell loss and disruption of normal islet function [5]. In this study we used the renal subcapsular site for implantation of a minimal islet mass. Our aims were to assess in a syngeneic mouse model of diabetes: (1) the effect of co-transplanting kidney-derived MSCs on the morphological and vascular engraftment; and (2) the function of the transplanted islets.

\section{Methods}

Experimental animals Male C567B1/6 mice (Charles River, Margate, UK) aged 8 to 12 weeks were used as donors and recipients of grafts. Mice were made diabetic by i.p. streptozotocin injection $(180 \mathrm{mg} / \mathrm{kg}$; Sigma-Aldrich, Poole, UK) and those with a non-fasting blood glucose concentration of $\geq 20 \mathrm{mmol} / \mathrm{l}$ were used as recipients. Blood glucose concentrations were determined using a blood glucose meter and strips (Accu-Chek; Roche, Burgess Hill, UK) with blood obtained from a pin prick to the tail. All animal procedures were approved by our institution's Ethics
Committee and carried out under licence, in accordance with the UK Home Office Animals (Scientific Procedures) Act 1986.

Islet isolation Islets were isolated by collagenase digestion ( $1 \mathrm{mg} / \mathrm{ml}$; type XI; Sigma-Aldrich) followed by density gradient separation (Histopaque-1077; Sigma-Aldrich). After washing with RPMI-1640 medium, islets were picked into groups of 150 for transplantation.

Mesenchymal stem cell isolation Kidney-derived MSCs were isolated from $\mathrm{C} 57 \mathrm{Bl} / 6$ mice as previously described [10]. Kidneys were rinsed in $\mathrm{Ca}^{2+}$ - and $\mathrm{Mg}^{2+}$-free Hanks' balanced salt solution containing $10 \mathrm{mmol} / \mathrm{l}$ sodium HEPES (Sigma-Aldrich) and cut into small pieces. The fragments were digested with collagenase type I $(1 \mathrm{mg} / \mathrm{ml}$; SigmaAldrich) for 30 to $45 \mathrm{~min}$ at $37^{\circ} \mathrm{C}$ and then triturated with a glass Pasteur pipette. Cells were pelleted by centrifugation for $10 \mathrm{~min}$ at $400 \times \mathrm{g}$ at room temperature. After this, cells were resuspended in DMEM supplemented with 1\% (vol./ vol.) penicillin/streptomycin solution (Gibco BRL, Gaithersburg, MD, USA) and 10\% (vol./vol.) FCS, seeded in six-well dishes $(3 \mathrm{ml} / \mathrm{well})$ and incubated at $37^{\circ} \mathrm{C}$ in a humidified atmosphere containing $5 \% \mathrm{CO}_{2}$. The medium was changed after $24 \mathrm{~h}$, with removal of non-adherent cells. When cultures reached confluence, cells were trypsinised and subcultured in new flasks, at passage ratios empirically determined for two subcultures a week.

Immunophenotyping Kidney-derived MSCs were analysed for the presence of surface markers by flow cytometry. MSCs at the fifth passage were trypsinised, resuspended in PBS and incubated with the following FITC- or phycoerythrinconjugated antibodies: CD11b, CD31, CD44, CD45, CD73, CD90.2 and stem cell antigen-1 (BD Pharmingen, San Diego, CA, USA). After $30 \mathrm{~min}$ incubation at $4^{\circ} \mathrm{C}$, the cells were washed and resuspended in $0.5 \mathrm{ml}$ PBS. Cells were analysed in a FACS calibur cytometer equipped with $488 \mathrm{~nm}$ argon laser (BD Pharmingen).

Adipogenic and osteogenic differentiation Adipogenic differentiation was induced by cultivation of confluent cultures in DMEM containing 20\% (vol./vol.) FCS, $2.5 \mu \mathrm{g} / \mathrm{ml}$ insulin, $100 \mu \mathrm{mol} / 1$ indomethacin, $5 \mu \mathrm{mol} / 1$ rosiglitazone and $10 \mathrm{nmol} / 1$ dexamethasone. For osteogenic differentiation, confluent cultures were cultivated in DMEM containing $10 \%$ (vol./vol.) FCS, $10 \mathrm{mmol} / 1$ B-glycerophosphate, $5 \mu \mathrm{g} / \mathrm{ml}$ ascorbic acid and $10 \mathrm{nmol} / 1$ dexamethasone. Cultures were maintained in differentiation media for 1 month with medium changes twice a week. Cell differentiation was analysed by staining with Oil Red O or Alizarin Red $\mathrm{S}$ for adipogenic and osteogenic differentiation, respectively, as described previously [10]. 
Transplantation Mice were transplanted with 150 freshly isolated islets either alone or together with $25 \times 10^{4}$ kidneyderived MSCs. The number of transplanted islets was chosen to act as a minimal islet mass, intended to reverse hyperglycaemia in only a proportion of diabetic recipients. A lumbar incision was made, the kidney exposed and an incision made in the capsule. Islets alone or islets+MSCs that had been centrifuged into pellets in PE50 polyethylene tubing (Becton Dickinson, Sparks, MD, USA) were placed underneath the kidney capsule using a Hamilton syringe (Fisher, Pittsburg, PA, USA).

Graft function The body weight and blood glucose concentrations of recipient mice were monitored every 3 to 4 days. Reversal of hyperglycaemia was defined as nonfasting blood glucose concentrations $\leq 11.1 \mathrm{mmol} / 1$ for at least two consecutive readings, without reverting to hyperglycaemia on any subsequent day. All mice with blood glucose $<11.1 \mathrm{mmol} / 1$ were given an intraperitoneal glucose tolerance test (IPGTT) 1 month after transplantation. Weight-matched, non-diabetic, non-transplanted male C567Bl/6 mice were used as controls. Fasting blood glucose concentrations were measured prior to i.p. injection of $2 \mathrm{~g} / \mathrm{kg}$ glucose and then after 15, 30, 60, 90 and $120 \mathrm{~min}$. In some animals, the islet graft-bearing kidneys were removed 2 days later to assess whether graft removal would result in a reversion to hyperglycaemia. Nephrectomised mice were killed 3 to 4 days later and the pancreas was also removed for histological examination. Other mice were killed so that the graft-bearing kidney and pancreas could be removed at the same time for analysis of hormone content or histological analysis.

Immunohistochemistry Graft bearing kidneys were fixed in $4 \%$ (vol./vol.) formalin and paraffin-embedded. Sections were stained for islet hormones and microvascular endothelial cells. For CD34 staining (detection of endothelial cells), antigen retrieval was required ( $2 \mathrm{~min}$ in $10 \mathrm{mmol} / \mathrm{l}$ citric acid solution, $\mathrm{pH} 6.0$ in a pressurised cooker). Sections were incubated for $1 \mathrm{~h}$ at room temperature in the appropriate primary antibody as follows: polyclonal guinea pig antiinsulin antibody $(1: 1,000$; Dako, Ely, UK), monoclonal mouse anti-glucagon antibody (1:1,000; Sigma-Aldrich), monoclonal rat anti-somatostatin antibody (1:50; AbCam, Cambridge, UK) or with a monoclonal rat anti-CD34 antibody (1:500; AbD Serotec, Kidlington, UK). Slides were then incubated for $1 \mathrm{~h}$ at room temperature with either a goat biotin anti-guinea pig antibody (1:200; Jackson Immunolaboratories, West Grove, PA, USA), a biotinylated link universal (Dako) or a rabbit biotinylated anti-rat antibody (1:200; Vector Laboratories, Peterborough, UK). Sections were incubated with streptavidin-horseradish peroxidase (Dako) and diaminobenzidine. For immunofluorescence labelling of insulin, a polyclonal guinea pig anti-insulin antibody (1:100; Jackson) was used ( $1 \mathrm{~h}$ at room temperature) with a Texas Red anti-guinea pig secondary antibody (1:40; Jackson; $1 \mathrm{~h}$ at room temperature).

Evaluation of graft morphology and vascular density For each animal five to nine tissue sections from different graft areas were evaluated for total endocrine area and vascular density. To evaluate the extent of islet fusion we measured the number and area of individual endocrine aggregates. An individual endocrine aggregate was defined as an area of insulin-positive tissue separated from any other adjacent insulin-positive tissue by $\geq 50 \mu \mathrm{m}$ of non-endocrine tissue (insulin-negative). Total endocrine area refers to the sum of the area of all endocrine aggregates within an individual graft section. The demarcation of the islet graft was taken as the area of endocrine and non-endocrine tissue between the renal parenchyma and the kidney capsule. The number of endothelial cells was counted by an individual blinded to the treatments. Areas of endocrine and non-endocrine tissue were counted separately. Area and diameter were determined using Image J software (http://rsbweb.nih.gov/ij/) and the vascular density (number of endothelial cells per square millimetre) was determined.

Hormone measurement of islet grafts and serum The islet graft-bearing kidneys or pancreas were homogenised in acidethanol ( $0.18 \mathrm{~mol} / \mathrm{l}$ in $70 \%$ [vol./vol.] ethanol) then sonicated. Tissue insulin, glucagon and somatostatin contents were measured using in-house RIA, as previously described [24, 25] and a commercially available somatostatin RIA kit (Euro-Diagnostica, Malmö, Sweden). Serum samples were obtained from non-fasted mice and insulin was measured using an ELISA (Mercodia, Uppsala, Sweden).

Statistical analysis Statistical analysis used Student's $t$ test or ANOVA, as appropriate. Two-way repeated-measurement ANOVA was used with Bonferroni's post hoc test to analyse repeated measurements in the same animal at different time points. When data sets were not normally distributed or did not have equal variance, ANOVA on ranks was performed. A Kaplan-Meier survival curve was used to identify differences in the time to cure between groups. A $p$ value of $p<$ 0.05 was considered significant. All data are expressed as means \pm SEM.

\section{Results}

MSC characterisation The characteristics of the adherent cells isolated from the whole kidney of male C57Bl/6 mice and expanded in vitro were similar to those previously 
described in detail by our group [10]. The cells presented morphological characteristics of MSCs and their identity was confirmed by flow cytometry immunophenotyping. Thus, the cells were negative for CD11b, CD31 and CD45, which are markers of macrophages, endothelial cells and haemopoietic cells, respectively, but positive for CD44, stem cell antigen-1, CD73 and CD90.2, which are characteristic of MSCs. Cells were also able to differentiate in vitro into adipocyte- and osteoblast-like cells, as assessed by histological staining with Oil Red O or Alizarin Red S.

Graft function Co-transplantation of islets with kidneyderived MSCs produced superior transplantation outcomes to islet-alone grafts, as shown in Fig. 1. The average blood glucose concentrations of mice transplanted with islets + MSCs were significantly lower than in mice transplanted with islets alone at 3, 7, 14, 21 and 28 days after transplantation (Fig. 1a). After 1 month, only $8 \%$ of mice transplanted with islets + MSCs had not reverted to hyperglycaemia, compared with $58 \%$ of mice transplanted with islets alone (Fig. 1b). The average time to reverse hyperglycaemia for islet+MSC grafts was $7 \pm 2$ days, with isletalone recipients taking significantly longer ( $17 \pm 2$ days, $p<$ $0.001, n=13)$. The median time to attain normoglycaemia was 4 and 17 days for islet+MSC and islet-alone grafts, respectively. There were no significant differences in the weights of mice in either transplant group on day $0(24.2 \pm$ 0.7 and $23.2 \pm 0.3 \mathrm{~g}$ for islet-alone and islet + MSC recipients, respectively, $n=13, p>0.2$ ) or at 1 month after transplantation $(25.9 \pm 0.7$ and $26.1 \pm 0.4 \mathrm{~g}, n=13, p>0.2)$. MSC-alone grafts did not lower blood glucose concentrations in streptozotocin-induced diabetic mice (day 0, 23.7 \pm $1.6 \mathrm{mmol} / \mathrm{l}$; day $3,23.4 \pm 4.1 \mathrm{mmol} / \mathrm{l}, n=3$ ), which had to be killed after a 3 day monitoring period due to excessive weight loss. Thus, MSCs alone had no capacity to reverse streptozotocin-induced diabetes. At 1 month after transplantation, non-fasted serum insulin concentrations were $432 \pm$ $114 \mathrm{pmol} / 1$ in islet+MSC mice vs $300 \pm 47 \mathrm{pmol} / 1$ in isletalone mice $(n=11, p=0.25)$. This was associated with lower blood glucose in the islet + MSC mice than in the islet-alone mice $(8.2 \pm 0.8 \mathrm{mmol} / 1$ vs $17.1 \pm 3.2 \mathrm{mmol} / 1, n=11, p=0.01)$. At this time-point, IPGTTs were carried out in all transplanted mice with blood glucose $<11.1 \mathrm{mmol} / 1$ and in weight-matched non-diabetic, non-transplanted controls. Glucose tolerance was similar in both transplant groups, but impaired in comparison to non-transplanted controls (Fig. 1c). At 2 days after the IPGTT, some of the mice with blood glucose $<11.1 \mathrm{mmol} / 1$ in each transplant group were nephrectomised, with all nephrectomised mice reverting to hyperglycaemia within 2 days.

Graft morphology Figure 2 shows the typical morphology of graft material retrieved 1 month after transplantation, demonstrating that islets co-transplanted with MSCs maintained a morphology that more closely resembles that of endogenous islets in the pancreas, in contrast to the amorphous mass of endocrine tissue that forms in isletalone grafts. Insulin immunostaining of islet-alone grafts revealed a single amorphous endocrine mass in the majority of sections analysed (Fig. 2a, c), where the transplanted islets have fused to form aggregated islet tissue. In contrast, there were rarely signs of any fusion between individual islets in the grafts of islet+MSC recipients. In these grafts, insulin immunostaining revealed endocrine aggregates with the appearance of normal islets separated by extensive areas of non-endocrine tissue (Fig. 2b, d). Although the total area of endocrine tissue per section (immunostained for insulin) was similar in islet-alone and islet+MSC grafts (Fig. 2e), it was clear that the graft morphology was different. We quantified the extent of islet fusion within the grafts of both
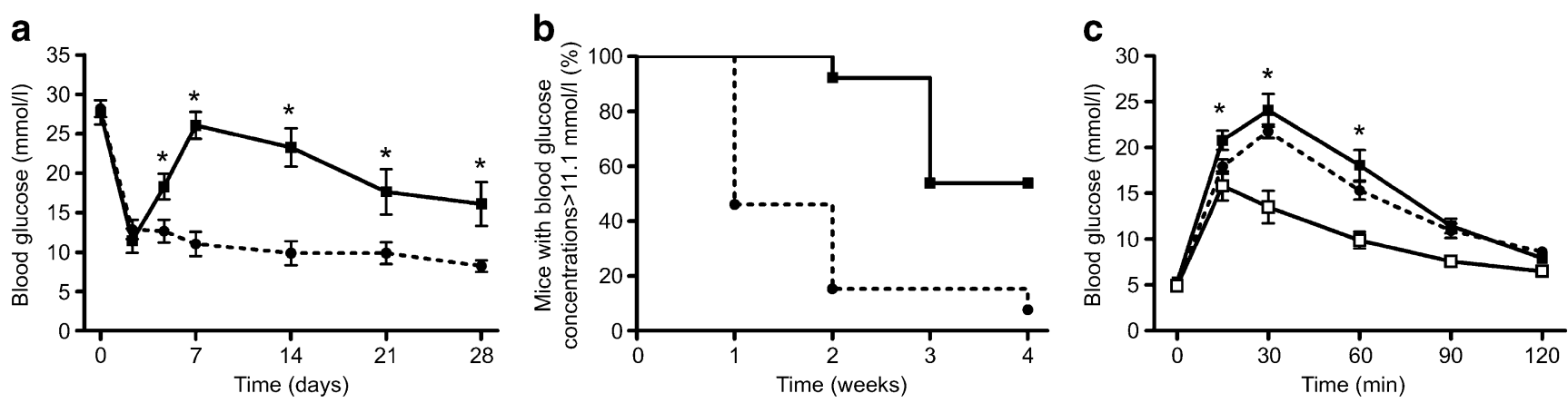

Fig. 1 Graft function. a Blood glucose concentrations of mice transplanted with 150 islets alone (continuous line) or those cotransplanted with 150 islets $+25 \times 10^{4}$ kidney-derived MSCs (dashed line); ${ }^{*} p<0.05$ vs mice transplanted with islets + MSCs (repeatedmeasurement ANOVA with Bonferroni post hoc test, $n=13$ ). b Percentage of mice remaining diabetic (blood glucose concentration $>11.1 \mathrm{mmol} / \mathrm{l}$ ) after transplantation as above (a); $p=0.0005$ Kaplan-
Meier, $n=13$ for both transplant groups. c IPGTTs in all mice with reversed hyperglycaemia after transplantion as above; IPGTT was conducted 4 weeks after transplantation. ${ }^{*} p<0.05$ vs non-diabetic non-transplanted controls (repeated-measurement ANOVA with Bonferroni post hoc test, $n=6-12$ ). Black squares, islets alone; black circles, islets+MSCs; white squares, control weight-matched, nondiabetic, non-transplanted mice 

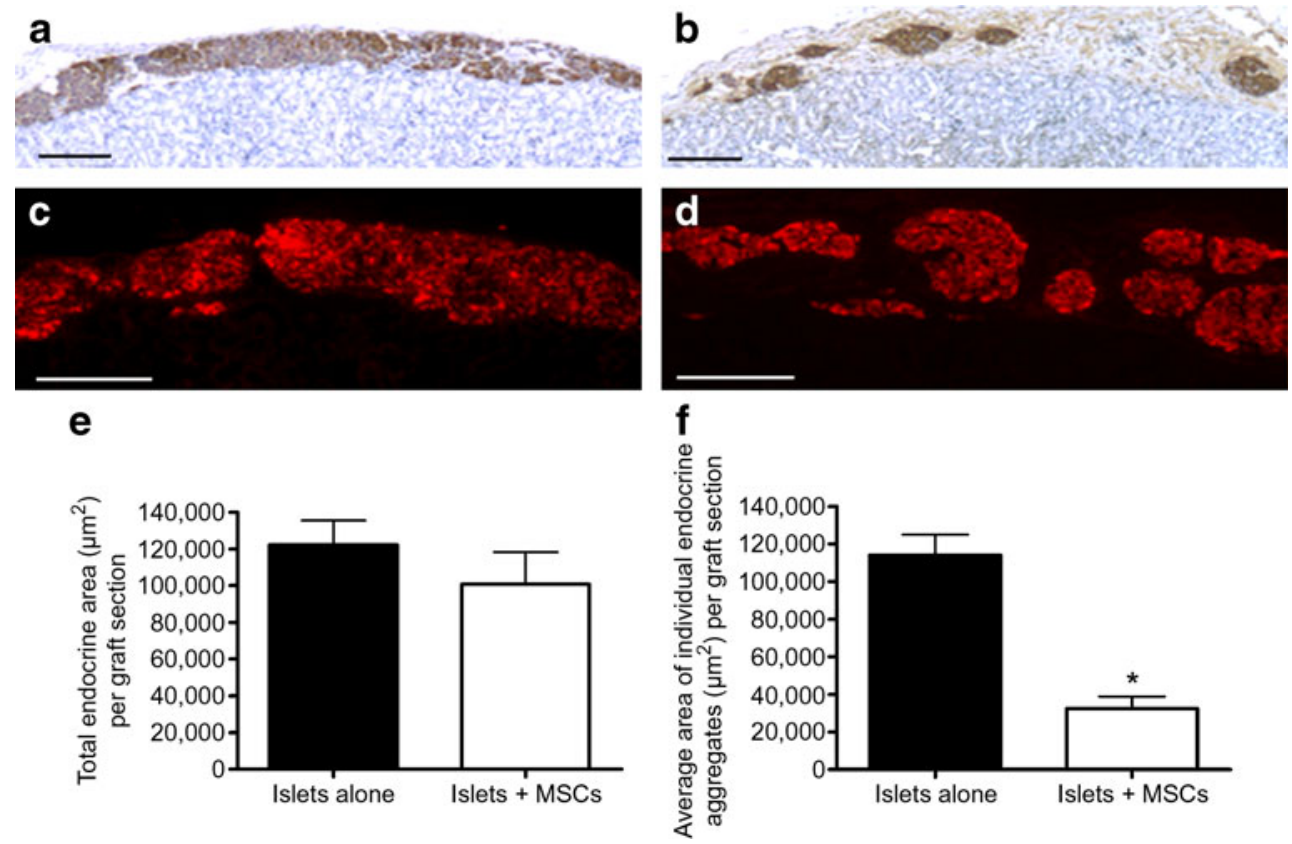

Fig. 2 Graft morphology. a, c Representative sections of islet-alone grafts and $(\mathbf{b}, \mathbf{d})$ islet+MSC grafts at 1 month post transplantation. a Islet-alone graft, where islets have aggregated to form a single amorphous endocrine mass. b Islet+MSC graft, where individual endocrine aggregates are separated by extensive areas of nonendocrine tissue. Original magnification $(\mathbf{a}, \mathbf{b}) \times 40$, scale bar $100 \mu \mathrm{m}$. c At a higher magnification $(\times 100)$, islet-alone graft shows that the rounded morphology of individual islets can no longer be

transplant groups by measuring the average area of each individual endocrine aggregate, defined as an individual mass of islet tissue that was separated from any adjacent endocrine aggregate by $\geq 50 \mu \mathrm{m}$ in each graft section. The average area of each single endocrine aggregate in islet+MSC recipients was approximately fourfold smaller than that of the aggregates in islet-alone recipients (Fig. 2f). The total graft area (endocrine+non-endocrine tissue) was higher in islet+MSC grafts than in islet-alone grafts $(322,596 \pm 38,919$ vs $134,546 \pm 14,941, p<0.05 t$ test, $n=4-6)$. Considering that the area of endocrine tissue was similar in both grafts, it was clear that the islet+MSC grafts contained large areas of non-endocrine tissue. Analysis of this tissue showed very few $\alpha$-smooth muscle actin-positive cells (a marker we have previously shown to stain murine MSCs [10]); rather, this tissue was predominately extracellular tissue, consisting of loosely packed fibres, staining positively with van Geison, which strongly indicates the presence of collagen.

Graft composition Immunostaining for glucagon-positive alpha cells indicated that the normal core-mantle segregation of islet endocrine cells was altered in the grafts of isletalone recipients, as shown in Fig. 3a. In contrast, the majority of alpha cells in islet + MSC grafts were located at

discerned, in comparison with (d) islet+MSC graft, where even when islets have aggregated, they still maintain a morphology comparable to that of endogenous islets in the pancreas, with individual islets still clearly distinguishable from each other. Scale bars, $100 \mu \mathrm{m}(\mathbf{c}, \mathbf{d})$. e Total endocrine area in graft sections; $n=4-6$ animals per group, $p>$ 0.2 Student's $t$ test. f Average individual endocrine aggregate area in graft sections; $n=4-6$ animals per group, $* p<0.05$ vs islet-alone grafts, Student's $t$ test

the periphery of individual islets (Fig. 3b). In both transplant groups, somatostatin-positive delta cells were dispersed among the alpha cells. As for the alpha cells, delta cells were distributed throughout the islet-alone grafts (Fig. 3c), whereas they were primarily located in the islet mantle in the islet+MSC grafts (Fig. 3d).

Hormone content At 1 month after transplantation there was considerable variation in the graft insulin content between animals, ranging from 3.0 to 15.2 and 7.7 to $21.1 \mu \mathrm{g} / \mathrm{graft}$ for islet-alone and islet+MSC recipients respectively. The mean insulin content of islet $+\mathrm{MSC}$ grafts was approximately $60 \%$ higher than in islet-alone grafts, but this was not statistically significant $(p>0.05$; Fig. 4a). The graft glucagon and somatostatin contents were similar between transplant groups (Fig. 4b, c). The insulin content of the pancreas in all streptozotocin-treated mice was around ten times lower than that of the grafts. There was no difference in the pancreas insulin content for mice transplanted with islets alone or islets + MSCs $(1.1 \pm 0.3$ and $1.9 \pm 0.4 \mu \mathrm{g} /$ pancreas, $p>0.2, n=4)$. Immunohistochemical analysis of the pancreas for each transplant group at 1 month after transplantation revealed very few insulinpositive cells (data not shown), consistent with the greatly reduced insulin content, providing further confirmation that 

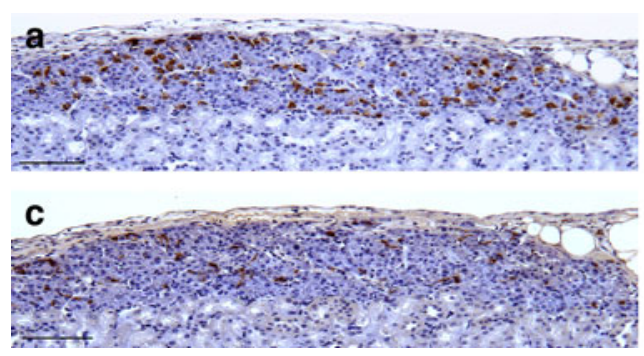

Fig. 3 Graft composition. Distribution of glucagon-positive alpha cells and somatostatin-positive delta cells. At 1 month after transplantation, consecutive sections were stained with glucagon $(\mathbf{a}, \mathbf{b})$ or somatostatin (c, d) antibodies, in grafts consisting of islets alone (a, c)

endogenous beta cell regeneration in the pancreas did not contribute significantly to maintenance of normoglycaemia.

Vascular density CD34 antibodies were used to immunostain microvascular endothelium in endogenous pancreatic islets (Fig. 5a) and in islet grafts beneath the kidney capsule (Fig. 5b-d). The distribution of CD34-positive endothelial cells in islet+MSC grafts was similar to that of islets in the pancreas, with endothelial cells located throughout the islet mass (Fig. 5b). In contrast, islet-alone grafts contained areas of endocrine tissue that were devoid of any endothelial cells, with no detectable differences being observed between hyperglycaemic and normoglycaemic recipients (Fig. 5c, d). We quantified the number of endothelial cells in the endocrine and non-endocrine tissue in the field of view by counting CD34-positive cells. The vascular density of the endocrine tissue in grafts consisting of islets +MSCs was significantly higher than that of isletalone grafts, as shown in Fig. 5e. However, the nonendocrine tissue in islet-alone grafts had a markedly higher vascular density than the non-endocrine tissue of islet + MSC grafts (Fig. 5e).

\section{Discussion}

We used a minimal islet mass transplantation model in streptozotocin-treated hyperglycaemic mice to demonstrate

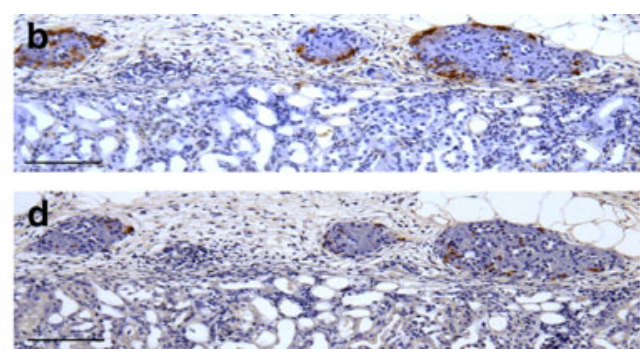

or islets + MSCs $(\mathbf{b}, \mathbf{d})$. Images are representative of sections from four to six different animals. Original magnification $\times 100$, scale bars $100 \mu \mathrm{m}$

that co-grafting kidney-derived MSCs with islets increased the rate and number of recipients attaining normoglycaemia by 1 month after transplantation. Several reports have indicated that MSCs have beneficial effects in different transplantation models, including islet grafts [12-19], and several different mechanisms have been thought to account for these effects, some of which are unlikely to account for our observations. Our results do not support the suggestion that transplantation of MSCs alone is sufficient to reverse hyperglycaemia in streptozotocin-treated rodents, either by enhancing regeneration of pancreatic beta cells [26] or through other paracrine effects [11]. Thus, transplanting MSCs alone did not reduce blood glucose in our streptozotocin-treated mice and MSC co-transplantation had no significant effect on the very low levels of pancreatic insulin and beta cell numbers up to 1 month after induction of hyperglycaemia. Other studies have suggested that the immunosuppressive properties of MSCs enhance islet survival after transplantation by secreting cytokines [15, 16, 18] or metalloproteinases [14]. This mechanism may be important in allogeneic grafts [12, 14$16,18]$, but immunomodulation is unlikely to be the sole mechanism accounting for the beneficial effects of MSCs in our syngeneic transplantation model.

MSCs secrete several trophic factors, many of which could have positive effects on islet cell viability and function in a co-transplant model [13, 27]. For example, in vitro co-culture experiments have shown that MSCs increase islet viability by upregulating anti-apoptotic genes
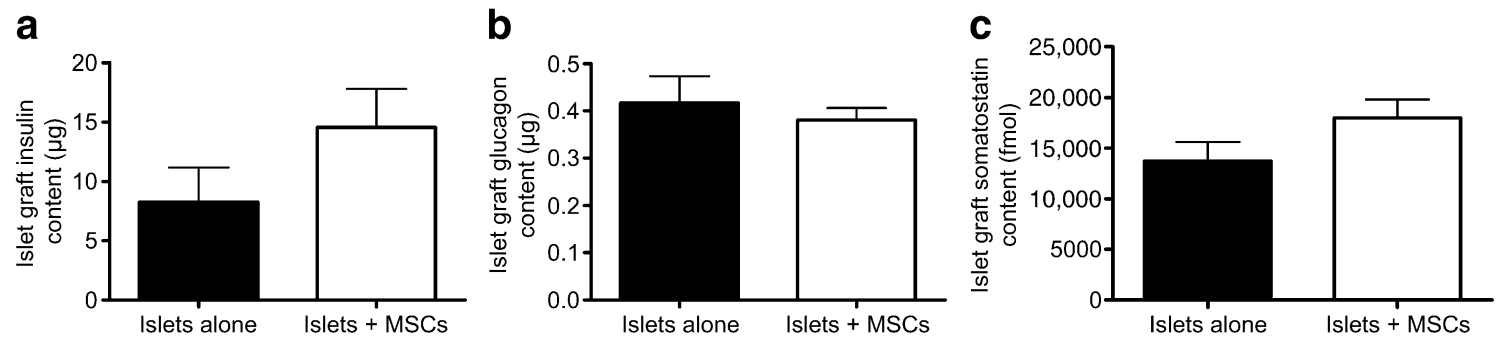

Fig. 4 Hormone content. a Insulin, (b) glucagon and (c) somatostatin content of grafts at 1 month after transplantation. Mice were transplanted with 150 islets alone (black bars) or 150 islets $+25 \times 10^{4}$ kidney-derived MSCs (white bars). $n=4, p>0.05$ by Student's $t$ test 


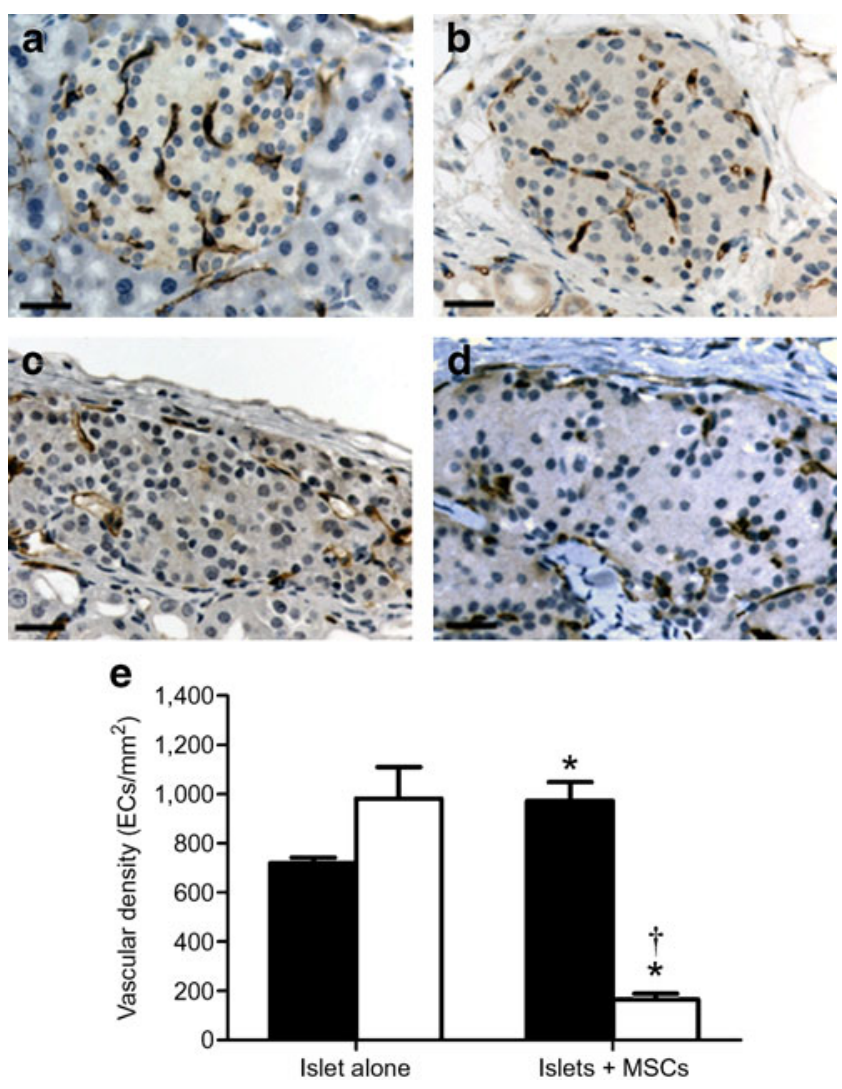

Fig. 5 Vascular density. Staining of endothelial cells (ECs) with CD34 antibodies in endogenous pancreatic islets (a), and in grafts of islet+MSC recipients with blood glucose $<11.1 \mathrm{mmol} / 1$ at 1 month after transplantation (b), of islet-alone hyperglycaemic recipients (c) and of islet-alone recipients with blood glucose $<11.1 \mathrm{mmol} / 1$ (d). Original magnification $\times 400$, scale bars $25 \mu \mathrm{m}$. e Vascular density of endocrine components (black bars) and non-endocrine components (white bars) in 1 month grafts consisting of 150 islets alone or 150 islets $+25 \times 10^{4}$ kidney-derived MSCs. ${ }^{*} p<0.05$ vs islet-alone and ${ }^{\dagger} p<$ 0.05 vs endocrine tissue within the same transplant group, by two-way ANOVA with Bonferroni's post hoc test

and improve insulin secretory function by modulating islet ATP content [27]. These effects are likely to be important in the immediate post-transplantation period when improved glycaemic control will favour effective islet engraftment by maintaining function $[6,28]$ and enhancing revascularisation [29]. These factors alone are unlikely to account for the beneficial effects of MSCs in our experiments. Thus, the presence of co-transplanted MSCs did not cause significant increases in graft insulin content and serum insulin at 1 month after transplantation, suggesting that the enhancing effects of MSCs on graft function may involve other factors. Although in contrast to a recent report [17], MSC co-transplantation enhanced the ability of islet grafts to reverse hyperglycaemia, it did not improve glucose tolerance in mice after reversal of hyperglycaemia. Islet-alone and islet+MSC grafts both showed similar degrees of impaired glucose tolerance when compared with nontransplanted control animals. This is presumably a conse- quence of the deliberately low insulin content in the minimal mass islet grafts. It should be noted that glucose tolerance tests were not carried out in hyperglycaemic mice. These data suggest that the presence of MSCs helps in the reversal of hyperglycaemia, but does not increase functionality after reversal of hyperglycaemia compared with isletalone grafts.

The rate of revascularisation of the islet graft is thought to have a major influence on graft survival and function, and on the reversal of hyperglycaemia [8]. Our results are consistent with previous observations that co-transplantation of MSCs improves islet revascularisation, at least in terms of endothelial cell numbers. MSCs derived from bone marrow [13] or pancreas [19] have been reported to increase the endothelial cell density of transplanted islets, consistent with a more effective revascularisation. MSCs may influence angiogenesis through several mechanisms. They secrete a range of angiogenic factors, including vascular endothelial growth factor, IL-6, IL-8, haemopoeitic growth factor and platelet-derived growth factor [19, 27, 30], which are known to enhance islet revascularisation [31-33]. In addition, MSCs secrete matrix metalloproteases [14], which facilitate migration of host-derived endothelial cells into the islets [34] degrading the extracellular matrix $[35,36]$.

Our morphological studies suggest that MSCs may also influence revascularisation and graft function by modulating the morphology of the graft. MSC co-transplantation had a profound impact on the remodelling process that occurs after transplantation, inducing a graft morphology that more closely represents that of islets in the endogenous pancreas, rather than the amorphous endocrine mass that formed at the graft site in islet-alone recipients as reported in previous islet transplantation studies [5, 6]. The MSCinduced changes in graft morphology were associated with an altered distribution of endothelial cells. Islet + MSC grafts showed a distribution of endothelial cells throughout the endocrine tissue, similar to that of islets in the pancreas, whereas the islet-alone grafts showed a largely peripheral distribution of endothelial cells, with large areas of endocrine tissue lacking endothelial cells. This is in accordance with previous studies demonstrating that the revascularisation of smaller islets after transplantation is more efficient than that of larger islets [37], an effect that is likely to be amplified by the large aggregates formed in our islet-alone grafts. The re-establishment of a blood supply is of obvious importance for the survival and function of the islets, but it is also clear that paracrine interactions between beta cells and endothelial cells are important in maintaining beta cell function [38]. The improved recovery of these interactions in the islet+MSC grafts may account for some beneficial effects of the MSC co-transplant in our model. Another striking observation from our analysis of endothelial cell distribution in the grafts was the low vascular 
density in the non-endocrine tissue surrounding the islets in the islet+MSC grafts, when compared with islet-alone grafts, in which the surrounding non-endocrine parenchyma contained large numbers of endothelial cells, as reported previously [39-41]. These observations are consistent with earlier reports that transplanted islets induce increased vascularisation of the surrounding tissue to compensate for their low vascular density [42]. The MSC-dependent increase in islet endothelial cell density observed by us may negate the requirement for a compensatory increase in revascularisation of the adjacent non-endocrine tissue.

The MSC-induced alterations in graft morphology are also likely to influence graft survival and function independently of the rate or extent of revascularisation. A recent study using encapsulated islets, which are unable to revascularise, demonstrated improved transplantation outcomes from grafting of aggregates of smaller islets rather than of larger intact islets, consistent with an anatomical effect on function that is independent of revascularisation or endothelial cell density [43]. It is well established that islet organisation influences function by facilitating the numerous interactions between the islet cells [44] that are required for normal insulin secretion $[45,46]$. The loss of organised islet anatomy in the islet-alone grafts, with alpha and delta cells distributed throughout the large endocrine aggregates is therefore likely to result in impaired function. Conversely, the MSC-dependent maintenance of normal islet size and organisation may contribute to the improved outcomes in the islet+MSC co-transplants. We did not see any evidence of MSCs remaining in the islet+MSC graft at 1 month, although they were detectable in grafts removed at 3 days. The non-endocrine component of the graft appeared to be largely composed of collagen fibres. Interestingly, in this context, Jalili et al. recently reported that a collagen matrix is beneficial to islet graft function [47].

In summary, we have demonstrated that co-transplantation of MSCs has a beneficial effect on the outcome of islet grafts for treatment of diabetic hyperglycaemia, confirming recent reports [12-18]. These effects may be due in part to enhanced revascularisation, as has been previously suggested $[13,17,19]$. However, our results also suggest that MSCdependent effects on the anatomical remodelling of the graft may have a major effect on graft function by maintaining islet organisation and morphology.

Acknowledgements We are grateful to the Biotechnology and Biological Sciences Research Council (C. L. Rackham), and the Research Councils UK and British Pharmacological Society Integrative Pharmacology Fund (A. J. F. King) for funding this study. We also thank CNPq-Brasil for the Sandwich scholarship (P. C. Chagastelles). This work was supported by the Novo Nordisk UK Research Foundation and the Animal Grant Initiative for Mammalian Biology operated by Charles River. The technical assistance of C. Hobbs is gratefully acknowledged.
Duality of interest The authors declare that there is no duality of interest associated with this manuscript.

\section{References}

1. Shapiro AM, Lakey JR, Ryan EA et al (2000) Islet transplantation in seven patients with type 1 diabetes mellitus using a glucocorticoid-free immunosuppressive regimen. N Engl J Med 343:230-238

2. Ryan EA, Paty BW, Senior PA et al (2005) Five-year follow-up after clinical islet transplantation. Diabetes 54:2060-2069

3. Fiorina P, Shapiro AM, Ricordi C, Secchi A (2008) The clinical impact of islet transplantation. Am J Transplant 8:1990-1997

4. Langer RM (2010) Islet transplantation: lessons learned since the Edmonton breakthrough. Transplant Proc 42:1421-1424

5. Davalli AM, Scaglia L, Zangen DH, Hollister J, Bonner-Weir S, Weir GC (1996) Vulnerability of islets in the immediate posttransplantation period. Dynamic changes in structure and function. Diabetes 45:1161-1167

6. Biarnes M, Montolio M, Nacher V, Raurell M, Soler J, Montanya E (2002) Beta-cell death and mass in syngeneically transplanted islets exposed to short- and long-term hyperglycemia. Diabetes 51:66-72

7. Miao G, Ostrowski RP, Mace J et al (2006) Dynamic production of hypoxia-inducible factor-1alpha in early transplanted islets. Am J Transplant 6:2636-2643

8. Brissova M, Powers AC (2008) Revascularization of transplanted islets: can it be improved? Diabetes 57:2269-2271

9. Menger MD, Jaeger S, Walter P, Feifel G, Hammersen F, Messmer K (1989) Angiogenesis and hemodynamics of microvasculature of transplanted islets of Langerhans. Diabetes 38(Suppl 1):199-201

10. da Silva ML, Chagastelles PC, Nardi NB (2006) Mesenchymal stem cells reside in virtually all post-natal organs and tissues. J Cell Sci 119:2204-2213

11. Xu YX, Chen L, Wang R et al (2008) Mesenchymal stem cell therapy for diabetes through paracrine mechanisms. Med Hypotheses 71:390-393

12. Jacobson S, Kumagai-Braesch M, Tibell A, Svensson M, Flodstrom-Tullberg M (2008) Co-transplantation of stromal cells interferes with the rejection of allogeneic islet grafts. Ann NY Acad Sci 1150:213-216

13. Figliuzzi M, Cornolti R, Perico N et al (2009) Bone marrowderived mesenchymal stem cells improve islet graft function in diabetic rats. Transplant Proc 41:1797-1800

14. Ding Y, Xu D, Feng G, Bushell A, Muschel RJ, Wood KJ (2009) Mesenchymal stem cells prevent the rejection of fully allogenic islet grafts by the immunosuppressive activity of matrix metalloproteinase-2 and -9. Diabetes 58:1797-1806

15. Solari MG, Srinivasan S, Boumaza I et al (2009) Marginal mass islet transplantation with autologous mesenchymal stem cells promotes long-term islet allograft survival and sustained normoglycemia. J Autoimmun 32:116-124

16. Longoni B, Szilagyi E, Quaranta P et al (2010) Mesenchymal stem cells prevent acute rejection and prolong graft function in pancreatic islet transplantation. Diabetes Technol Ther 12:435446

17. Ito T, Itakura S, Todorov I et al (2010) Mesenchymal stem cell and islet co-transplantation promotes graft revascularization and function. Transplantation 89:1438-1445

18. Berman DM, Willman MA, Han D et al (2010) Mesenchymal stem cells enhance allogeneic islet engraftment in nonhuman primates. Diabetes 59:2558-2568

19. Sordi V, Melzi R, Mercalli A et al (2010) Mesenchymal cells appearing in pancreatic tissue culture are bone marrow-derived 
stem cells with the capacity to improve transplanted islet function. Stem Cells 28:140-151

20. Merani S, Toso C, Emamaullee J, Shapiro AM (2008) Optimal implantation site for pancreatic islet transplantation. Br J Surg 95:1449-1461

21. Morini S, Braun M, Onori P et al (2006) Morphological changes of isolated rat pancreatic islets: a structural, ultrastructural and morphometric study. J Anat 209:381-392

22. Morini S, Brown ML, Cicalese L et al (2007) Revascularization and remodelling of pancreatic islets grafted under the kidney capsule. J Anat 210:565-577

23. King AJ, Fernandes JR, Hollister-Lock J, Nienaber CE, BonnerWeir S, Weir GC (2007) Normal relationship of beta and non-beta cells not needed for successful islet transplantation. Diabetes 56:2312-2318

24. Bjaaland T, Hii CS, Jones PM, Howell SL (1988) Role of protein kinase $\mathrm{C}$ in arginine-induced glucagon secretion from isolated rat islets of Langerhans. J Mol Endocrinol 1:105-110

25. Jones PM, Salmon DM, Howell SL (1988) Protein phosphorylation in electrically permeabilized islets of Langerhans. Effects of $\mathrm{Ca}^{2+}$, cyclic AMP, a phorbol ester and noradrenaline. Biochem J 254:397-403

26. Dong QY, Chen L, Gao GQ et al (2008) Allogeneic diabetic mesenchymal stem cells transplantation in streptozotocin-induced diabetic rat. Clin Invest Med 31:E328-E337

27. Park KS, Kim YS, Kim JH et al (2009) Influence of human allogenic bone marrow and cord blood-derived mesenchymal stem cell secreting trophic factors on ATP (adenosine-5'-triphosphate)/ ADP (adenosine-5'-diphosphate) ratio and insulin secretory function of isolated human islets from cadaveric donor. Transplant Proc 41:3813-3818

28. Makhlouf L, Duvivier-Kali VF, Bonner-Weir S, Dieperink H, Weir GC, Sayegh MH (2003) Importance of hyperglycemia on the primary function of allogeneic islet transplants. Transplantation 76:657-664

29. Vasir B, Reitz P, Xu G, Sharma A, Bonner-Weir S, Weir GC (2000) Effects of diabetes and hypoxia on gene markers of angiogenesis (HGF, cMET, uPA and uPAR, TGF-alpha, TGFbeta, bFGF and vimentin) in cultured and transplanted rat islets. Diabetologia 43:763-772

30. Golocheikine A, Tiriveedhi V, Angaswamy N, Benshoff N, SabariNathan R, Mohanakumar T (2010) Cooperative signaling for angiogenesis and neovascularization by VEGF and HGF following islet transplantation. Transplantation 90:725-731

31. Brissova M, Shostak A, Shiota M et al (2006) Pancreatic islet production of vascular endothelial growth factor-a is essential for islet vascularization, revascularization, and function. Diabetes 55:2974-2985

32. Cabric S, Sanchez J, Johansson U et al (2010) Anchoring of vascular endothelial growth factor to surface-immobilized heparin on pancreatic islets: implications for stimulating islet angiogenesis. Tissue Eng A 16:961-970
33. Movahedi B, Gysemans C, Jacobs-Tulleneers-Thevissen D, Mathieu C, Pipeleers D (2008) Pancreatic duct cells in human islet cell preparations are a source of angiogenic cytokines interleukin-8 and vascular endothelial growth factor. Diabetes $57: 2128-2136$

34. Johansson U, Rasmusson I, Niclou SP et al (2008) Formation of composite endothelial cell-mesenchymal stem cell islets: a novel approach to promote islet revascularization. Diabetes 57:23932401

35. Ghajar CM, Blevins KS, Hughes CC, George SC, Putnam AJ (2006) Mesenchymal stem cells enhance angiogenesis in mechanically viable prevascularized tissues via early matrix metalloproteinase upregulation. Tissue Eng 12:2875-2888

36. Potapova IA, Gaudette GR, Brink PR et al (2007) Mesenchymal stem cells support migration, extracellular matrix invasion, proliferation, and survival of endothelial cells in vitro. Stem Cells 25:1761-1768

37. Kampf C, Mattsson G, Carlsson PO (2006) Size-dependent revascularization of transplanted pancreatic islets. Cell Transplant 15:205-209

38. Johansson A, Lau J, Sandberg M, Borg LA, Magnusson PU, Carlsson PO (2009) Endothelial cell signalling supports pancreatic beta cell function in the rat. Diabetologia 52:2385-2394

39. Mattsson G, Jansson L, Nordin A, Carlsson PO (2003) Impaired revascularization of transplanted mouse pancreatic islets is chronic and glucose-independent. Transplantation 75:736-739

40. Olsson R, Carlsson PO (2005) Better vascular engraftment and function in pancreatic islets transplanted without prior culture. Diabetologia 48:469-476

41. Lau J, Carlsson PO (2009) Low revascularization of human islets when experimentally transplanted into the liver. Transplantation 87:322-325

42. Mattsson G, Jansson L, Carlsson PO (2002) Decreased vascular density in mouse pancreatic islets after transplantation. Diabetes 51:1362-1366

43. O'Sullivan ES, Johnson AS, Omer A et al (2010) Rat islet cell aggregates are superior to islets for transplantation in microcapsules. Diabetologia 53:937-945

44. Carvell MJ, Marsh PJ, Persaud SJ, Jones PM (2007) E-cadherin interactions regulate beta-cell proliferation in islet-like structures. Cell Physiol Biochem 20:617-626

45. Bosco D, Orci L, Meda P (1989) Homologous but not heterologous contact increases the insulin secretion of individual pancreatic B cells. Exp Cell Res 184:72-80

46. Hauge-Evans AC, King AJ, Carmignac D et al (2009) Somatostatin secreted by islet delta-cells fulfills multiple roles as a paracrine regulator of islet function. Diabetes 58:403-411

47. Jalili RB, Rezakhanlou AM, Hosseini-Tabatabaei A, Ao Z, Warnock GL, Ghahary A (2011) Fibroblast populated collagen matrix promotes islet survival and reduces the number of islets required for diabetes reversal. J Cell Physiol. doi:10.1002/ jcp. 22515 